\title{
Prognostic Value of Immunohistochemical Expressions of the Stem Cell Biomarker "LGR5" and the Proliferation Biomarker "TPX2" in Colorectal Carcinoma
}

\author{
Ola A Harb, Abdelmonem A Hegazy, Loay M Gertallah, Rasha Haggag, Shereen El Shorbagy
}

\author{
Ola A Harb, Pathology, Faculty of Medicine, Zagazig University, \\ Zagazig 44519, Egypt \\ Abdelmonem A Hegazy, Anatomy and Embryology, Faculty of \\ Medicine, Zagazig University, Zagazig 44519, Egypt \\ Loay M Gertallah, General surgery, Faculty of Medicine, Zagazig \\ University, Zagazig 44519, Egypt \\ Rasha Haggag, Shereen El Shorbagy, Medical Oncology, Faculty \\ of Medicine, Zagazig University, Zagazig 44519, Egypt \\ Correspondence to: Abdelmonem A Hegazy, Anatomy and \\ Embryology, Faculty of Medicine, Zagazig University, Zagazig 44519, \\ Egypt. \\ Email: dr.abdelmonemhegazy@yahoo.com \\ Telephone: +201110504321 \\ Fax: +20552307830 \\ Received: April 9, 2016
}

Revised: June 3, 2016

Accepted: June 7, 2016

Published online: June 29, 2016

\section{ABSTRACT}

AIM: Colorectal carcinoma (CRC) is the commonest and most deathly malignant gastrointestinal tumors. Carcinogenic process starts in a group of cancer cells, called cancer stem cells (CSCs) having the ability to start and maintain tumor growth and invasion. In order to detect and remove colon CSCs, a selective biomarker "LGR5 (leucine-rich-repeat-containing G-protein-coupled receptor 5)" might be required. At the same time, an abnormal expression of TPX2 (targeting protein for xenopus kinesin-like protein 2) has been found to be related to the development and progression of tumors. We aimed to evaluate the immunohistochemical expressions of LGR5 and TPX2 in CRC in a trial to clarify their relations to proliferation and metastasis of CRC, and hence its prognosis.

MATERIALS AND METHODS: Immunohistochemical staining of both LGR5 and TPX2 was assessed in sections from sixty paraffin blocks of CRC. The relationships between their levels of expressions with the clinicopathological parameters and patient outcome were statistically analyzed.

RESULTS: The immunoexpression of LGR5 in CRC was signifi- cantly positively correlated with location of the tumor, grade, stage, local recurrence, lymph node and distant metastasis $(P<0.001)$. The expression of TPX2 in CRC was also found to be significantly correlated with the previous parameters $(P<0.001)$. Both biomarkers were up-regulated in $\mathrm{CRC}$ than in the adjacent non tumorous tissues. High LGR5 and TPX2 immunohistochemical expressions were strongly correlated with worse 3-year overall survival (OS), local recurrence free survival (LRFS) and distant metastases free survival (DMFS) $(P<0.001)$.

CONCLUSIONS: High immunohistochemical expressions of both LGR5 and TPX2 and the positive correlation between both of them represent signs of poor prognosis of CRC.

Key words: Stem cell; Colorectal cancer; LGR5; TPX2; Metastases; Prognosis

C 2016 The Authors. Published by ACT Publishing Group Ltd.

Harb OA, Hegazy AA, Gertallah LM, Haggag R, El Shorbagy S. Prognostic Value of Immunohistochemical Expressions of the Stem Cell Biomarker "LGR5" and the Proliferation Biomarker "TPX2" in Colorectal Carcinoma. Journal of Tumor 2016; 4(3): 426-434 Available from: URL: http://www.ghrnet.org/index.php/jt/article/ view/1665

\section{INTRODUCTION}

Colorectal cancer (CRC) is the commonest and most fatal malignant gastrointestinal tumors ${ }^{[1]}$. The major causes of CRC related death are local recurrence and lymphatic and hematogenous metastases ${ }^{[2]}$.

Mechanisms responsible for the initiation, progression, prognosis and adequate management of $\mathrm{CRC}$ have been studied ${ }^{[3]}$. Two theories of CRC carcinogenesis have been stated; a stochastic model, where any cell has the ability of cancer initiation, promotion and progression and a cancer stem cell (CSC) model, that only produced by transformed CSCs having the ability to self-renewal, abnormally differentiate and form a cancer ${ }^{[4]}$. Although, CSCs have been incriminated in colon carcinogenesis for several years, the complexity of their detection and isolation is still not precisely 
clarified $^{[5]}$. CSCs are resistant to chemotherapeutic agents and responsible for recurrence and spread of CRC. Continuous research about CRC is essential to identify novel therapeutics specifically targeting $\mathrm{CSCs}^{[6]}$. G-protein-coupled receptors (GPCRs) are transmembrane proteins which after combination to their ligand activate cytoplasmic G-proteins stimulating many intracellular enzymes. They have important roles in many cellular activities, such as tissue repair, inflammation and carcinogenesis ${ }^{[7]}$. LGR5 is a member of the largest family of cell-surface molecules of the GPCRs. It is expressed on intestinal stem cells, where it functions as a transducer of Wnt signaling ${ }^{[8]}$. LGR5+ cells have been detected in the crypt stem cells (precursor cells) and gastric mucosal lesions that progressed to cancer ${ }^{[9]}$. It predominantly restricted to the base of mature pyloric glands in the adults ${ }^{[10]}$. Many treatment protocols have been applied to CRC, but they have not resulted in a complete cure. This may be due to colorectal CSCs that are resistant to radiation therapy and chemotherapy, and may enable the recurrence of cancers. Therefore, it is important to use therapies that target not only proliferating cells but also stem cells in order to treat the tumor ${ }^{[11]}$. In order to detect and remove such CSCs, a selective marker is required. Becker et al suggested that LGR5 may be a novel biomarker for CSCs in cases of $\mathrm{CRC}^{[12]}$.

At the same time, TPX2, a microtubule-associated protein was initially stated by Heidebrecht et $a l^{[13]}$. It has been found to be a nuclear proliferation-related protein which is implicated in the regulation of the cell mitosis. TPX2 is released in the early stage of mitosis; and plays a critical role in mitotic spindle formation and subsequent segregation of chromosomes at cell division ${ }^{[14]}$. In recent years, a connection between TPX2 and initiation, progression and prognosis of malignant tumor is becoming a focus of researches ${ }^{[15]}$. Previous studies showed that abnormally high expression of TPX2 has been confirmed in many tumor tissues ${ }^{[16,17]}$. TPX2 can upregulate expression of matrix metalloproteinases (MMP) family through activating PI3K/Akt pathway. Therefore, inhibiting its expression through downregulating expressions of MMP2 and MMP9 can inhibit the invasion of liver cancer cells ${ }^{[18]}$. Moreover, TPX2 expression is obviously upregulated in breast cancer in comparison to the adjacent tissues. Nevertheless, the connection between TPX2 and prognosis, and specific molecular mechanism still need further research ${ }^{[19]}$. Despite its overexpression in many tumors, its role in CRC remains to be vague.

This study aimed to evaluate immunohistochemical expression of the stem cell biomarker "LGR5" and the proliferation biomarker "TPX2" in CRC in a trial to clarify the relations between their expressions with the proliferation and metastasis of the tumor, and to detect any correlation to its prognosis.

\section{MATERIALS AND METHODS}

\section{Patients and tissue specimens}

For this retrospective cohort study, 60 archival formalin-fixed paraffin-embedded blocks of CRC cases collected from Pathology Department, Faculty of Medicine, Zagazig University. Samples were obtained by partial and radical colectomy done in general surgery department, Faculty of Medicine, Zagazig University, between December 2012 and December 2015. The seventh edition of the American Joint Committee on Cancer staging system (AJCC-7) classification was used for pathologic staging ${ }^{[20]}$. At the same time, the World Health Organization (WHO) classification was performed for pathologic grading ${ }^{[21]}$.

We identified sex, age, tumor size, histological subtype, grade, stage, lymph node and distant metastasis of the cases by retrospective examination of the medical records and the slide files of the pathology department. Most patients had follow-up records for three years in Medical Oncology Department, Faculty of Medicine, Zagazig University. Others died within such period of follow-up. The study was performed after patients' consents with full local ethics approval.

\section{Immunohistochemical staining}

Immunohistochemical staining was carried out using the streptavidinbiotin immunoperoxidase technique ${ }^{[22]}$. Five $\mu \mathrm{m}$ thick sections were cut from paraffin-embedded blocks of all cases, put on positively charged slides, and then de-paraffinized in xylene and rehydrated in ascending grades of ethanol. Antigen ratreival was done by boiling sections in citrate buffer ( $\mathrm{pH} \mathrm{6.0)}$ ) for $20 \mathrm{~min}$. Then after washing with phosphate buffered saline (PBS), the slides were incubated with primary rabbit polyclonal Anti-GPCR GPR49/LGR5 antibody ab71225 (Abcam, Cambridge, MA, USA) diluted 1:50 in blocking solution; and primary mouse monoclonal anti-TPX2 antibody 18D5-1 ab32795 was used at a dilution of 1:200. at $4{ }^{\circ} \mathrm{C}$ overnight. The sections were then washed in PBS and incubated with Polyperoxidase-anti-mouse/rabbit IgG (Zymed Laboratories, San Francisco, CA, USA) for $20 \mathrm{~min}$. After washing with PBS, 3, 30-Diaminobenzidine was used as the chromogen. Finally, the sections were counterstained with hematoxylin.

Specimens of esophageal adenocarcinoma were used as positive controls for LGR5 ${ }^{[23]}$. Tissue sections that previously stained positive for TPX-2 were used as the positive controls ${ }^{[24]}$. The negative controls used the non-immune isotype serum instead of the primary antibodies.

\section{Evaluation of immunostaining intensity of LGR5 proteins}

Evaluation was analyzed according to both the percentage of positive cells and the intensity of staining. The intensity was graded from 0 to 3 ; with 0 records as no staining, 1 as mild, 2 as moderate and 3 as strong. The highest intensity score was assigned when a threshold of $>10 \%$ of cells stained with that intensity. Percentage of stained cells was also scored from 0 to 3 , where immunoreactivity was scored 0 if no carcinoma cells stained positive, 1 if $1 \%$ to $25 \%$ were positive, 2 if $25 \%$ to $50 \%$ were positive, and 3 if $>50 \%$ were positive. A composite expression score [0-6] was obtained by adding the intensity and percentage scores, with 1-2 recorded as weak positive $[+], 3-4$ as moderate positive $[++]$, and $5-6$ as strong positive $[+++]$. In the statistical analysis, 0 was ranked as negative and 1-6 was recorded as positive. Score of 1-2 was ranked as low expression, and 3-6 recorded as high expression ${ }^{[23]}$.

\section{Evaluation of immunostaining intensity of TPX2}

The TPX2 labeling index (LI) was ranked according to the percentage of positive cells. The staining intensity was graded as follows; 0 : no staining, 1+: mild staining, 2+: moderate staining, and 3+: intense staining. The staining was scored as the following; 0 : no staining of cells, $1+:<10 \%$ of tissue stained positive, $2+: 10 \%-50 \%$ stained positive, and $3+:>50 \%$ stained positive. The sum of staining score (intensity + extension) index was designated as follows; 0-2: negative expression, 3-4: low expression and 5-6: high expression ${ }^{[25]}$.

\section{Statistical analysis}

All statistics were performed using SPSS 22.0 for windows (SPSS Inc., Chicago, IL, USA) and MedCalc windows (MedCalc Software bvba 13, Ostend, Belgium). Continuous variables were expressed 


\begin{tabular}{|c|c|c|c|c|c|c|c|c|c|c|c|c|}
\hline \multirow[t]{3}{*}{ Characteristics } & \multirow{2}{*}{\multicolumn{2}{|c|}{$\begin{array}{l}\text { All } \\
(n=60)\end{array}$}} & \multicolumn{4}{|c|}{ LGR-5 } & \multirow[t]{3}{*}{$P$-value } & \multicolumn{4}{|c|}{ TPX-2 } & \multirow[t]{3}{*}{$P$-value } \\
\hline & & & \multicolumn{2}{|c|}{ Low $(n=32)$} & \multicolumn{2}{|c|}{ High $(n=28)$} & & \multicolumn{2}{|c|}{ Low $(n=34)$} & \multicolumn{2}{|c|}{ High $(n=26)$} & \\
\hline & No. & $(\%)$ & No. & $(\%)$ & No. & $(\%)$ & & No. & $(\%)$ & No. & $(\%)$ & \\
\hline \multicolumn{13}{|l|}{ Age (years) } \\
\hline Mean \pm SD & 57.46 & \pm 12.42 & 50.25 & \pm 10.86 & 65.71 & \pm 8.35 & $<0.001^{\ddagger}$ & 51.02 & \pm 11.23 & 65.88 & \pm 8.22 & $<0.001^{\ddagger}$ \\
\hline Median (Range) & 61 & $(35-80)$ & 50 & $(35-77)$ & 67.5 & $(45-80)$ & & 50 & $(35-77)$ & 67.5 & $(50-80)$ & \\
\hline$\leq 60$ years & 30 & $(50 \%)$ & 26 & $(81.30 \%)$ & 4 & $(14.30 \%)$ & $<0.001^{\S}$ & 26 & $(76.50 \%)$ & 4 & $(15.40 \%)$ & $<0.001^{\S}$ \\
\hline$>60$ years & 30 & $(50 \%)$ & 6 & $(18.80 \%)$ & 24 & $(85.70 \%)$ & & 8 & $(23.50 \%)$ & 22 & $(84.60 \%)$ & \\
\hline \multicolumn{13}{|l|}{ Sex } \\
\hline Male & 37 & $(61.70 \%)$ & 18 & $(56.30 \%)$ & 19 & $(67.90 \%)$ & $0.356^{\S}$ & 20 & $(58.80 \%)$ & 17 & $(65.40 \%)$ & $0.604^{\S}$ \\
\hline Female & 23 & $(38.30 \%)$ & 14 & $(43.80 \%)$ & 9 & $(32.10 \%)$ & & 14 & $(41.20 \%)$ & 9 & $(34.60 \%)$ & \\
\hline \multicolumn{13}{|l|}{ Location } \\
\hline Right colon & 29 & $(48.30 \%)$ & 8 & $(25 \%)$ & 21 & $(75 \%)$ & $<0.001^{\S}$ & 11 & $(32.40 \%)$ & 18 & $(69.20 \%)$ & $0.020^{\S}$ \\
\hline Transverse colon & 6 & $(10 \%)$ & 3 & $(9.40 \%)$ & 3 & $(10.70 \%)$ & & 3 & $(8.80 \%)$ & 3 & $(11.50 \%)$ & \\
\hline Left colon & 6 & $(10 \%)$ & 6 & $(18.80 \%)$ & 0 & $(0 \%)$ & & 5 & $(14.70 \%)$ & 1 & $(3.80 \%)$ & \\
\hline Sigmoid colon & 19 & $(31.70 \%)$ & 15 & $(46.90 \%)$ & 4 & $(14.30 \%)$ & & 15 & $(44.10 \%)$ & 4 & $(15.40 \%)$ & \\
\hline \multicolumn{13}{|l|}{ Size $(\mathrm{cm})$} \\
\hline Mean \pm SD & 5.68 & \pm 2.77 & 3.96 & \pm 0.89 & 7.64 & \pm 2.89 & $<0.001^{\ddagger}$ & 4.41 & \pm 1.90 & 7.34 & \pm 2.86 & $<0.001^{\ddagger}$ \\
\hline Median (Range) & 5 & $(2-12)$ & 4 & $(2-6)$ & 8 & $(3-12)$ & & 4 & $(2-12)$ & 8 & $(3-12)$ & \\
\hline$\leq 5 \mathrm{~cm}$ & 40 & $(66.70 \%)$ & 31 & $(96.90 \%)$ & 9 & $(32.10 \%)$ & $<0.001^{\mathrm{s}}$ & 31 & $(91.20 \%)$ & 9 & $(34.60 \%)$ & $<0.001^{\S}$ \\
\hline$>5 \mathrm{~cm}$ & 20 & $(33.30 \%)$ & 1 & $(3.10 \%)$ & 19 & $(67.90 \%)$ & & 3 & $(8.80 \%)$ & 17 & $(65.40 \%)$ & \\
\hline \multicolumn{13}{|l|}{ Pathological Type } \\
\hline Adenocarcinoma & 55 & $(91.70 \%)$ & 32 & $(100 \%)$ & 23 & $(82.10 \%)$ & $0.013^{\S}$ & 33 & $(97.10 \%)$ & 22 & $(84.60 \%)$ & $0.084 \S$ \\
\hline Mucinous & 5 & $(8.30 \%)$ & 0 & $(0 \%)$ & 5 & $(17.90 \%)$ & & 1 & $(2.90 \%)$ & 4 & $(15.40 \%)$ & \\
\hline \multicolumn{13}{|l|}{ Grade } \\
\hline Grade 1 & 10 & $(16.70 \%)$ & 10 & $(31.30 \%)$ & 0 & $0 \%$ & $<0.001^{\circ}$ & 10 & $(29.40 \%)$ & 0 & $(0 \%)$ & $<0.001^{\circ}$ \\
\hline Grade 2 & 38 & $(63.30 \%)$ & 22 & $(68.80 \%)$ & 16 & $(57.10 \%)$ & & 23 & $(67.60 \%)$ & 15 & $(57.70 \%)$ & \\
\hline Grade 3 & 12 & $(20 \%)$ & 0 & $(0 \%)$ & 12 & $(42.90 \%)$ & & 1 & $(2.90 \%)$ & 11 & $(42.30 \%)$ & \\
\hline \multicolumn{13}{|l|}{ Lymph node } \\
\hline Negative & 30 & $(50 \%)$ & 24 & $(75 \%)$ & 6 & $(21.40 \%)$ & $<0.001^{\S}$ & 24 & $(70.60 \%)$ & 6 & $(23.10 \%)$ & $<0.001^{\S}$ \\
\hline Positive & 30 & $(50 \%)$ & 8 & $(25 \%)$ & 22 & $(78.60 \%)$ & & 10 & $(29.40 \%)$ & 20 & $(76.90 \%)$ & \\
\hline \multicolumn{13}{|l|}{ Stage } \\
\hline Stage I & 10 & $(16.70 \%)$ & 10 & $(31.30 \%)$ & 0 & $0 \%$ & $<0.001^{\circ}$ & 10 & $(29.40 \%)$ & 0 & $(0 \%)$ & $<0.001^{\circ}$ \\
\hline Stage II & 20 & $(33.30 \%)$ & 14 & $(43.80 \%)$ & 6 & $(21.40 \%)$ & & 14 & $(41.20 \%)$ & 6 & $(23.10 \%)$ & \\
\hline Stage III & 18 & $(30 \%)$ & 8 & $(25 \%)$ & 10 & $(35.70 \%)$ & & 8 & $(23.50 \%)$ & 10 & $(38.50 \%)$ & \\
\hline Stage IV & 12 & $(20 \%)$ & 0 & $(0 \%)$ & 12 & $(42.90 \%)$ & & 2 & $(5.90 \%)$ & 10 & $(38.50 \%)$ & \\
\hline \multicolumn{13}{|l|}{ LGR5 } \\
\hline Mean \pm SD & 34.83 & \pm 34.04 & 7.81 & \pm 10.37 & 65.71 & \pm 23.55 & $<0.001^{\ddagger}$ & 12.64 & \pm 21.17 & 63.84 & \pm 24.46 & $<0.001^{\ddagger}$ \\
\hline Median (Range) & 23.5 & $(0-95)$ & 0 & $(0-24)$ & 75 & $(30-95)$ & & 0 & $(0-85)$ & 70 & $(20-95)$ & \\
\hline Low & 32 & $(53.30 \%)$ & & & & & & 31 & $(91.20 \%)$ & 1 & $(3.80 \%)$ & $<0.001^{\mathrm{s}}$ \\
\hline High & 28 & $(46.70 \%)$ & & & & & & 3 & $(8.80 \%)$ & 25 & $(96.20 \%)$ & \\
\hline \multicolumn{13}{|l|}{ TPX2 } \\
\hline Mean \pm SD & 41.33 & \pm 34.17 & 16.09 & \pm 17.76 & 70.17 & \pm 23.90 & $<0.001^{\ddagger}$ & 14.55 & \pm 16.57 & 76.34 & \pm 11.96 & $<0.001^{\ddagger}$ \\
\hline Median (Range) & 37.5 & $(0-90)$ & 10 & $(0-55)$ & 75 & $(0-90)$ & & 0 & $(0-45)$ & 77.5 & $(55-90)$ & \\
\hline Low & 34 & $(56.70 \%)$ & 31 & $(96.90 \%)$ & 3 & $(10.70 \%)$ & $<0.001^{\S}$ & & & & & \\
\hline High & 26 & $(43.30 \%)$ & 1 & $(3.10 \%)$ & 25 & $(89.30 \%)$ & & & & & & \\
\hline
\end{tabular}

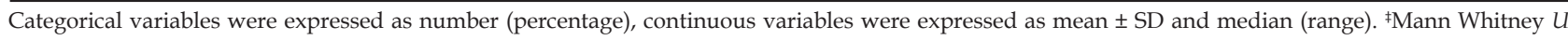
test; ${ }^{\circledR}$ Chi-square test; ${ }^{\circ}$ Chi-square test for trend; $P<0.05$ is significant.

as the mean $\pm \mathrm{SD}$ and median (range), and the categorical variables were expressed as a number (percentage). Percentages of categorical variables were compared using the Pearson's Chi-square test or Fisher's exact test when was appropriate. Strength of relationship between LGR5 and TPX2 and clinicopathological features were determined by computing Spearman's correlation coefficient. Stratification of OS, LRFS and DMFS was done according to all clinicopathological features and immunohistochemical markers and were estimated using the method of Kaplan-Meier plot. A $P$-value < 0.05 was considered statistically significant.

\section{RESULTS}

\section{Patients}

The investigated 60 cases were 37 males and 23 females, with age ranged from 35-80 years (mean: $57.46 \pm 12.42$ ) (Table 1). There were $55(91.7 \%)$ cases of conventional adenocarcinoma and $5(8.3 \%)$ cases of mucinous carcinoma. Ten (16.7\%) cases were grade I, 38 $(63.3 \%)$ cases were grade II, $12(20 \%)$ cases were grade III. At the same time, $10(16.7 \%)$ cases were stage I, $20(33.3 \%)$ cases were stage II, $18(30 \%)$ cases were stage III and $12(20 \%)$ cases were stage IV (Table 1).

\section{LGR5 immunoexpression and its correlation with clinicopathological features}

LGR5 was cytoplasmic and membranous. Its high immunohistochemical expression in CRC was detected in 28 (47\%) cases and low expression in $32(53 \%)$ cases. In grade I, the low expression was detected in 10/10 cases and the high expression not detected in any case. In grade II, the low expression was detected in 22/38 cases and the high expression detected in 16/38 cases. In grade III the low expression was not detected in any case and the high expression detected in 12/12 cases. In stage I, the low expression was detected in 10/10 cases and the high expression not detected in any case. In stage II, the low expression was detected in 


\begin{tabular}{|c|c|c|c|c|c|c|c|c|c|c|c|}
\hline \multirow{2}{*}{ Characteristics } & \multirow{2}{*}{\multicolumn{2}{|c|}{$\begin{array}{l}\text { All } \\
(n=60)\end{array}$}} & \multicolumn{2}{|c|}{ Local recurrence } & \multirow{2}{*}{$P$-value } & \multicolumn{2}{|c|}{ Distant metastasis } & \multirow{2}{*}{$P$-value } & \multicolumn{2}{|l|}{ Survival } & \multirow[t]{2}{*}{$P$-valuc } \\
\hline & & & No $(n=37)$ & Yes $(n=23)$ & & No $(n=48)$ & Yes $(n=12)$ & & Alive $(n=42)$ & Died $(n=18)$ & \\
\hline \multicolumn{12}{|l|}{ LGR5 } \\
\hline Mean \pm SD & 34.83 & \pm 34.04 & $14.18 \pm 20.92$ & $68.04 \pm 22.85$ & $<0.001^{\ddagger}$ & $21.66 \pm 23.79$ & $87.50 \pm 3.98$ & $<0.001^{\ddagger}$ & $18.69 \pm 24.34$ & $72.5 \pm 21.16$ & $<0.001^{\ddagger}$ \\
\hline Median (Range) & 23.5 & $(0-95)$ & $0(0-85)$ & $80(30-95)$ & & $20(0-80)$ & $87.5(80-95)$ & & $16.5(0-95)$ & $82.5(30-90)$ & \\
\hline Low & 32 & $(53.30 \%)$ & $32(100 \%)$ & $0(0 \%)$ & $<0.001^{\mathrm{s}}$ & $32(100 \%)$ & $0(0 \%)$ & $<0.001^{\S}$ & $32(100 \%)$ & $0(0 \%)$ & $<0.001^{\mathrm{s}}$ \\
\hline High & 28 & $(46.70 \%)$ & $5(17.9 \%)$ & $23(82.1 \%)$ & & $16(57.1 \%)$ & $12(42.9 \%)$ & & $10(35.7 \%)$ & $18(64.3 \%)$ & \\
\hline \multicolumn{12}{|l|}{ TPX2 } \\
\hline Mean \pm SD & 41.33 & \pm 34.17 & $20.81 \pm 23.49$ & $74.34 \pm 19.49$ & $<0.001^{\ddagger}$ & $33.22 \pm 29.18$ & $73.75 \pm 34.51$ & $<0.001^{\ddagger}$ & $26.54 \pm 27.17$ & $75.83 \pm 21.70$ & $<0.001^{\ddagger}$ \\
\hline Median (Range) & 37.5 & $(0-90)$ & $20(0-90)$ & $80(0-90)$ & & $30(0-80)$ & $90(0-90)$ & & $25(0-90)$ & $82.5(0-90)$ & \\
\hline Low & 34 & $(56.70 \%)$ & 33 (97.1\%) & $1(2.9 \%)$ & $<0.001^{\mathrm{s}}$ & 32 (94.1\%) & $2(5.9 \%)$ & $0.002^{\mathrm{s}}$ & $33(97.1 \%)$ & $1(2.9 \%)$ & $<0.001^{\mathrm{s}}$ \\
\hline High & 26 & $(43.30 \%)$ & $4(15.4 \%)$ & $22(84.6 \%)$ & & $16(61.5 \%)$ & $10(38.5 \%)$ & & $9(34.6 \%)$ & $17(65.4 \%)$ & \\
\hline
\end{tabular}

Categorical variables were expressed as number (percentage), continuous variables were expressed as mean \pm SD \& median (range). ${ }^{\ddagger}$ Mann $W h i t n e y ~ U$ test; ${ }^{\S}$ Chi-square test; ${ }^{\circ}$ Chi-square test for trend; $P<0.05$ is significant.

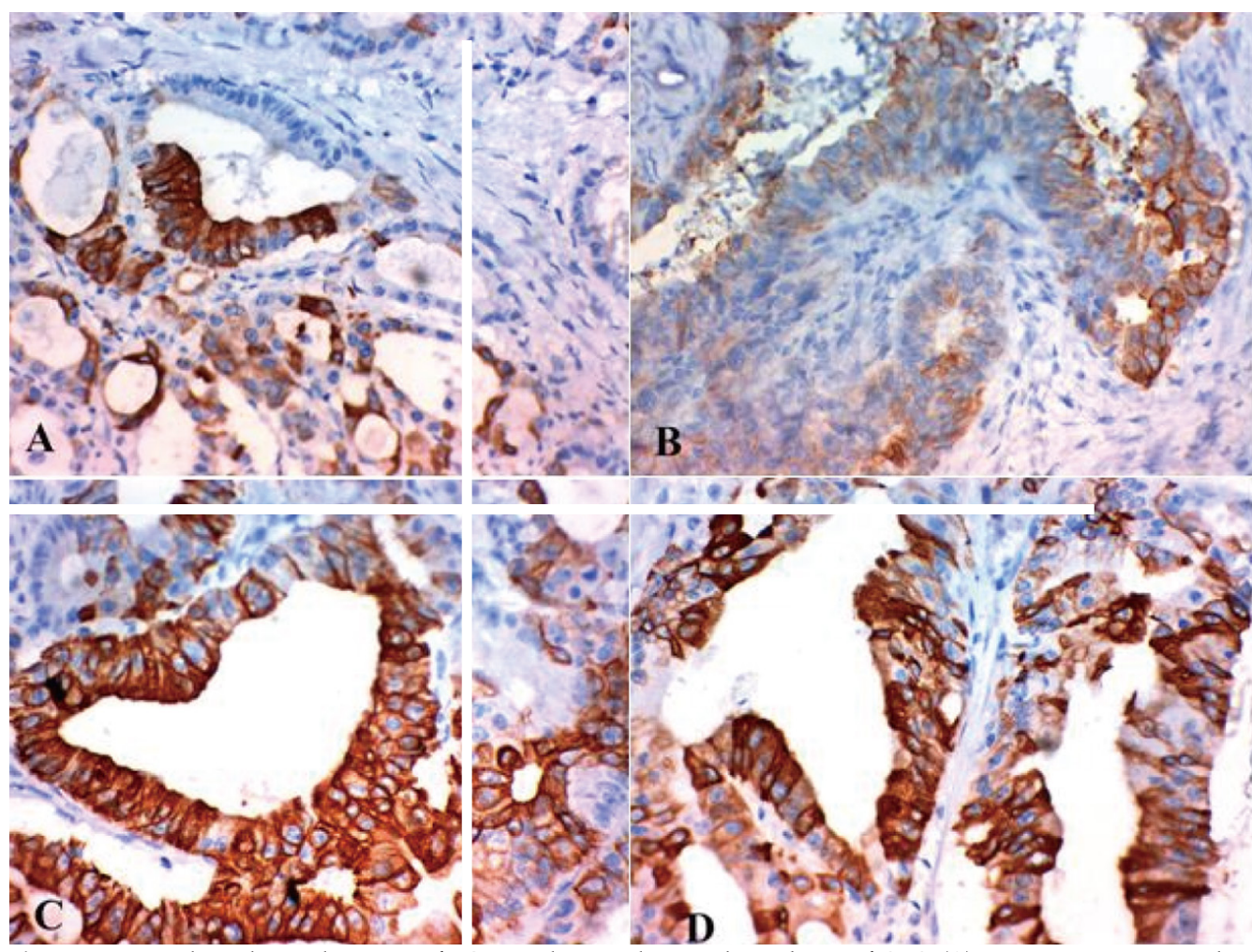

Figure 1 Immunohistochemical staining of LGR5 in the cytoplasm and membrane of CRC: (A) Low expression in grade I stage I CRC $\times 400$; (B) Low expression in grade II, stage II CRC $\times 400$; (C) High Immunohistochemical expression in grade II stage III CRC $\times 400$; (D) High Immunohistochemical expression in grade II, stage IV CRC $\times 400$.

$14 / 20$ cases and the high expression detected in 6/20 cases. In stage III, the low expression was detected in 8/18 case and the high expression detected in 10/18 cases. Finally in stage IV, the low expression was not detected in any case and the high expression detected in 12/12 cases. Low immunohistochemical expression of LGR5 was detected in all adjacent non-tumor tissues compared to CRC tissue that mean that LGR5 was down regulated in non-tumor tissues and up-regulated in CRC tissue.

The high immunohistochemical expression of LGR5 in CRC was significantly positively correlated with location of the tumor, grade, stage, lymph node and distant metastasis $(P<0.001)$ (Figure 1; Tables 1 and 2).

TPX2 immunoexpression and its correlation with clinicopathological features

Only manifest nuclear staining was defined as a positive reaction of TPX2. Its high immunohistochemical expression in CRC was detected in 26 (43\%) cases and low expression in 34 (57\%) cases. In grade I, the low expression was detected in 10/10 cases and the high expression was not detected in any case. In grade II, the low expression was detected in 23/38 cases and the high expression detected in $15 / 38$ cases. In grade III, the low expression was detected in $1 / 12$ case and the high expression detected in $11 / 12$ cases. In stage I, the low expression was detected in $10 / 10$ cases and the high expression was not detected in any case. In stage II, the low expression was detected in 14/20 cases and the high expression was detected in $6 / 20$ cases. In stage III, the low expression was detected in $8 / 18$ case and the high expression was detected in 10/18 cases. In stage IV, the low expression was detected in $2 / 12$ cases and the high expression detected in 10/12 cases. Low immunohistochemical expression of TPX2 was detected in all non-tumor tissues compared to CRC tissue that mean that TPX2 was down regulated in non-tumor tissue and up regulated in $\mathrm{CRC}$ tissue.

The high expression of TPX2 in CRC was significantly positively 
Harb OA et al. LGR5 and TPX2 in colorectal carcinoma

\begin{tabular}{|c|c|c|c|c|c|c|c|c|}
\hline & \multicolumn{2}{|c|}{ LGR-5 (\%) } & \multicolumn{2}{|l|}{ LGR-5 } & \multicolumn{2}{|c|}{ TPX-2 (\%) } & \multicolumn{2}{|l|}{ TPX-2 } \\
\hline & $r$ & $P$-value & $r$ & $P$-value & $r$ & $P$-value & $r$ & $P$-value \\
\hline Age (years) & +0.665 & $<0.001$ & +0.626 & $<0.001$ & +0.637 & $<0.001$ & +0.597 & $<0.001$ \\
\hline Sex & -0.156 & 0.235 & +0.118 & 0.356 & -0.097 & 0.462 & +0.067 & 0.604 \\
\hline Location & -0.337 & 0.008 & +0.48 & $<0.001$ & -0.362 & 0.004 & +0.375 & 0.02 \\
\hline Size $(\mathrm{cm})$ & +0.703 & $<0.001$ & +0.667 & $<0.001$ & +0.573 & $<0.001$ & +0.529 & $<0.001$ \\
\hline Type & +0.484 & $<0.001$ & +0.307 & 0.013 & +0.264 & 0.042 & +0.218 & 0.084 \\
\hline Grade & 0.511 & $<0.001$ & +0.604 & $<0.001$ & +0.501 & $<0.001$ & +0.553 & $<0.001$ \\
\hline pT & 0.561 & $<0.001$ & +0.762 & $<0.001$ & +0.484 & $<0.001$ & +0.624 & $<0.001$ \\
\hline Lymph node & +0.686 & $<0.001$ & +0.471 & $<0.001$ & +0.551 & $<0.001$ & +0.426 & $<0.001$ \\
\hline Stage & +0.739 & $<0.001$ & +0.707 & $<0.001$ & +0.643 & $<0.001$ & +0.6 & $<0.001$ \\
\hline LGR-5 (\%) & --- & --- & --- & --- & +0.849 & $<0.001$ & +0.751 & $<0.001$ \\
\hline LGR-5 & -- & -- & --- & --- & +0.796 & $<0.001$ & +0.655 & $<0.001$ \\
\hline TPX-2 (\%) & +0.849 & $<0.001$ & +0.796 & $<0.001$ & --- & --- & --- & -- \\
\hline TPX-2 & +0.751 & $<0.001$ & +0.655 & $<0.001$ & -- & -- & -- & -- \\
\hline
\end{tabular}

$r$ correleation coefficient; $P<0.05$ is significant.

\begin{tabular}{|c|c|c|c|c|c|c|c|c|c|}
\hline Markers & TP & FP & TN & FN & $\mathrm{SN} \%$ & SP $\%$ & PPV \% & NPV \% & Accuracy \\
\hline & No (\%) & No (\%) & No (\%) & No (\%) & $(95 \%$ CI $)$ & $(95 \% \mathrm{CI})$ & $(95 \% \mathrm{CI})$ & $(95 \% \mathrm{CI})$ & $(95 \%$ CI $)$ \\
\hline LGR5 (high) & $22(36.7 \%)$ & $6(10 \%)$ & $24(40 \%)$ & $8(13.3 \%)$ & $73.30 \%(57.5-89.2)$ & $80 \%(65.7-94.3)$ & $78.60 \%(63.4-93.8)$ & $75 \%(60-90)$ & $76.70 \%(66-87.4)$ \\
\hline TPX-2 (high) & $20(33.3 \%)$ & $6(10 \%)$ & $24(40 \%)$ & $10(16.7 \%)$ & $66.70 \%(49.8-83.5)$ & $80 \%(65.7-94.3)$ & $76.90 \%(60.7-93.1)$ & $70.60 \%$ & $73.30 \%(62.1-84.5)$ \\
\hline $\begin{array}{l}\text { LGR5 (high) and } \\
\text { TPX-2 (high) }\end{array}$ & $22(36.7 \%)$ & $7(11.7 \%)$ & $23(38.3 \%)$ & $8(13.3 \%)$ & $73.30 \%(57.5-89.2)$ & $76.70 \%(61.5-91.8)$ & $75.90 \%(60.3-91.4)$ & $74.20 \%(58.8-89.6)$ & $75 \%(64-86)$ \\
\hline
\end{tabular}

TP: True positive; FP: False positive; TN: True negative; FN: False negative; SN: Sensitivity; SP: Specificity; PPV: Positive Predictive Value; NPV: Negative Predictive Value, $95 \% \mathrm{CI}$ : $95 \%$ Confidence Interval; $P<0.05$ is significant.

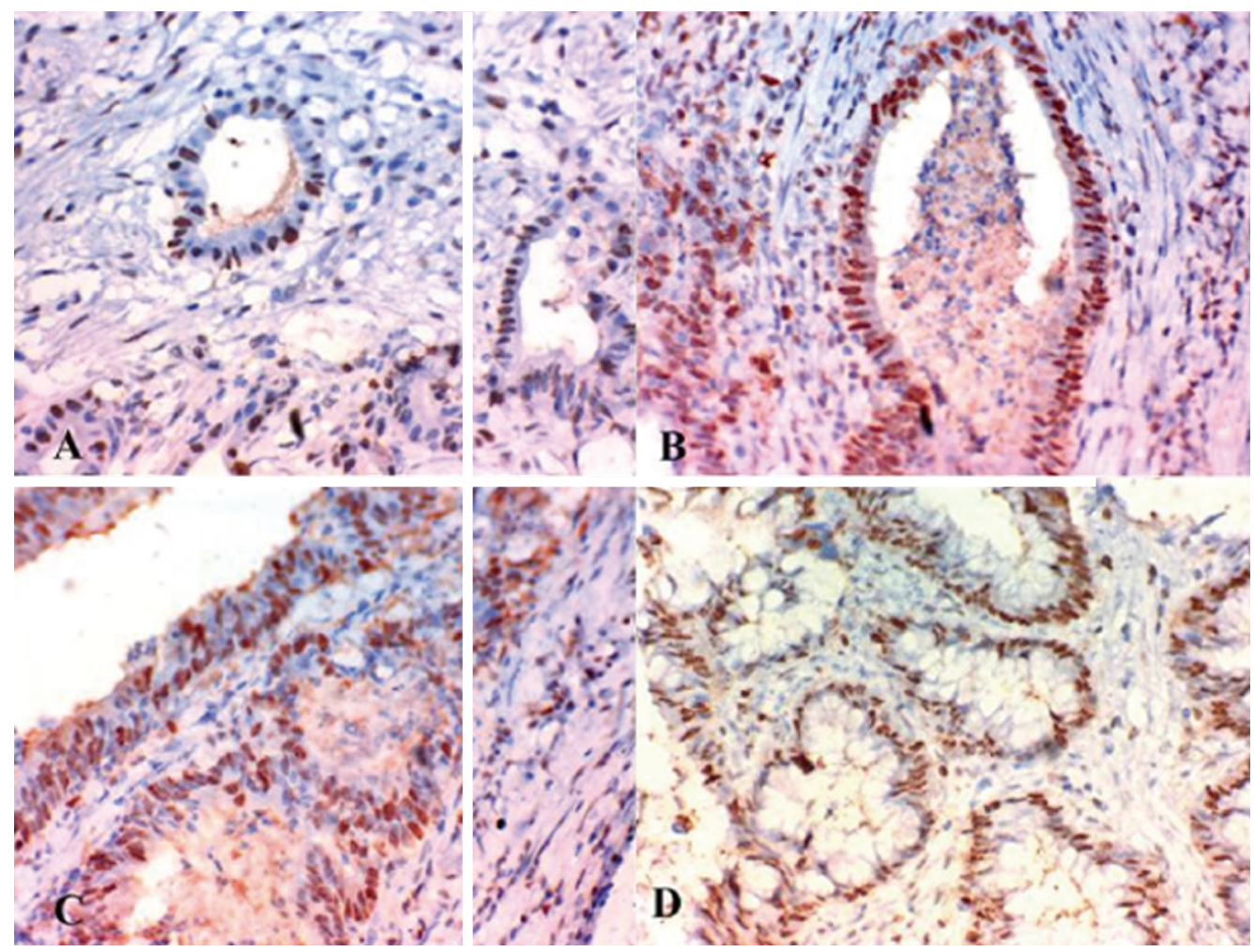

Figure 2 Immunohistochemical nuclear staining of TPX2 in CRC: (A) Low expression in grade I, stage I CRC $\times 400$; $(B)$ High expression in grade II, stage II CRC $\times 400$; (C) High expression in grade II, stage III CRC $\times 400$; (D) High expression in mucinous carcinoma grade II, stage III CRC $\times 400$.

correlated with location of the tumor, grade, stage, lymph node and distant metastasis $(P<0.001)$ (Figure 2; Tables 1 and 2).

\section{Immunoexpression correlations of LGR5 with TPX2}

Immunohistochemical expressions of LGR5 and TPX2 were significantly positively correlated with each other correlation coefficient $\mathrm{r}=+0.849(P<0.001)$ (Figure 3; Table 3).

The sensitivity of combination of both markers as predictors for advanced stage of CRC was $73.3 \%$; and the specificity was $76.7 \%$ (Table 4). 


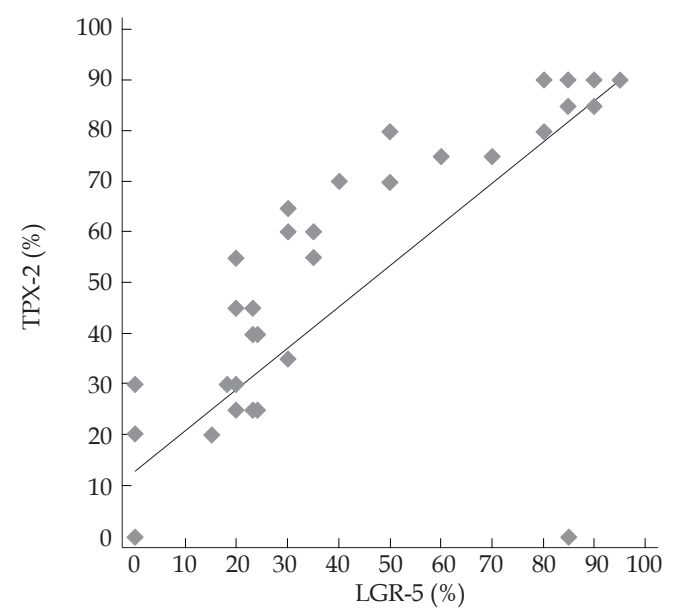

Figure 3 Scatter plot with regression line shows a significant strong direct correlation between LGR-5 and TPX-2 $(r=+0.849$, $P<0.001)$.

\section{Follow-up results}

The 3-year overall survival (OS) rate was $69.2 \%$ in all cases and $24.1 \%$ in high LGR5, 100\% in low LGR5, 23.2\% in high TPX2 and $100 \%$ in low TPX2 expressions.

The 3-year local recurrence free survival (LRFS) rate was $61.7 \%$ in all cases and $17.9 \%$ in high LGR5, 100\% in low LGR5, 15.4\% in high TPX2 and $97.1 \%$ in low TPX2 expressions.

The 3-year distant metastases free survival (DMFS) rate of our cases was $78.5 \%$ in all cases and $33.6 \%$ in high LGR5, 100\% in low LGR5, $42.7 \%$ in high TPX2 and $94.1 \%$ in low TPX2 expressions.

There was a highly significant inverse relationship between both high LGR5 and high TPX2 immunohistochemical expressions and 3 -year OS, LRFS and DMFS rates $(P<0.001)$ (Figures 4 and 5 ; Table 5).

\section{DISCUSSION}

In our study regarding the stem cell biomarker "LGR5", its increased expression in CRC in comparison to non-tumorous tissue and was was significantly positively correlated with location, stage, grade of the tumor, lymph node and distant metastasis $(P<0.001)$. These results suggest that high expression levels of LGR5 receptors are usually correlated with more malignant and metastatic potential of CRC. We also found that the immune- expression of LGR5 in CRC was significantly associated with shortened progression-free OS and DMFS $(P<0.001)$. Our results suggest that LGR5 is involved in the growth and progression of CRC and it may be an important biological marker of its invasion and metastasis. Our results are consistent with previous studies proving that overexpression of LGR5 was associated with poor prognosis in $\mathrm{CRC}^{[26-29]}$. The current results also are consistent with studies done in other organs stating that LGR5 overexpression is associated with poor prognosis and metastasis-initiating potentials in breast cancer, glioblastoma, lung cancer and esophageal adenocarcinoma ${ }^{[30-33]}$.

Similar to the previous report proved by Becker et $a l^{[12]}$, we found that LGR5 is a promising biomarker of SCs and cancer stem cells (CSCs). It was up-regulated in CRC in comparison to nontumorous tissue. There was increased immunoexpression of the biomarker with increasing grade and stage and associated with poor prognosis. LGR5-positive CRC may contain more CSCs than nontumorous tissue. Therefore, in agreement with CSC theories, the
A

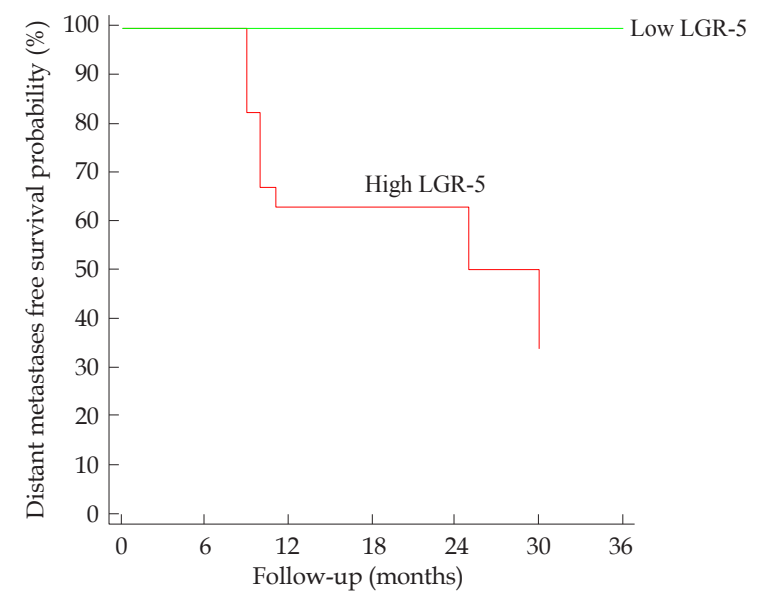

B

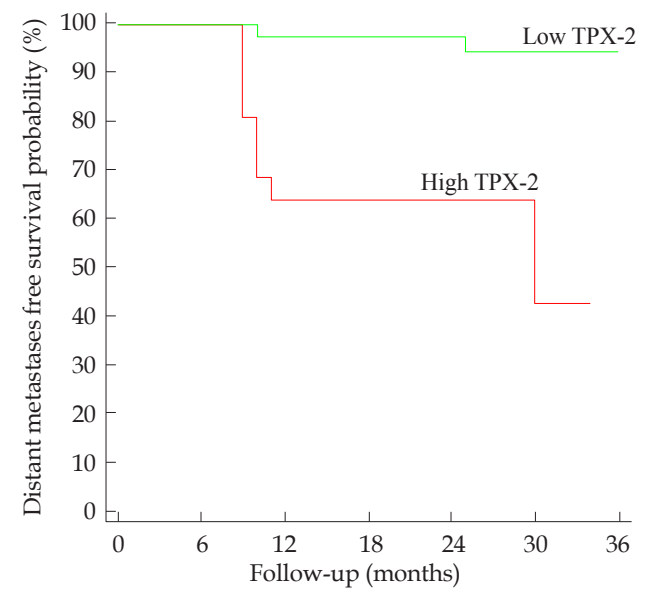

Figure 4 Kaplan-Meier plot of distant metastasis free survival: (A) stratified according to LGR5; (B) stratified according to TPX2.

residual CSCs may lead to metastasis and recurrence of colorectal cancer through multilineage differentiation and self-renewal after surgical resection of the primary cancer ${ }^{[34]}$. Discovering a novel stem cell biomarker such as LGR5 which its expression was associated with poor prognosis, recurrence and metastases of CRC can help to detect therapeutic modality targeting CSCs through eradicating LGR5 positive CSCs and leading to decrease progression recurrence, metastases and improving the CRC prognosis. Since year 2002, George et al was trying to prove the role of therapeutic drugs that target GPCRs in clinical use $\mathrm{e}^{[35]}$. Then, Hanahan et al, found that targeting cancer stem cells (CSCs) might be a novel approach to improve patient prognosis ${ }^{[36]}$.

Concerning the immune- expression of TPX2 in CRC, it was upregulated in $\mathrm{CRC}$ tissue in comparison to non-tumorous tissue and was significantly positively correlated with location of the tumor, stage, grade, lymph node and distant metastasis $(P<0.001)$, and was significantly positively correlated with shortened OS and DMFS $(P<$ $0.001)$. Our results are consistent with that of Wei et al ${ }^{[25]}$, suggesting that overexpression of TPX2 is associated with poor prognosis in colon cancer. Our results also are consistent with studies done in other organs proving that TPX2 overexpression is associated with poor prognosis in cancer of various organs including cervix, bladder and esophagus ${ }^{[16,37,38]}$.

There were several mechanisms that can explain the role of TPX2 in carcinogenesis process. It plays an important role in DNA damage stress, initiation, progression and spread of cancer ${ }^{[15]}$. It can also 


\begin{tabular}{|c|c|c|c|c|c|c|c|c|c|c|c|}
\hline \multirow[t]{3}{*}{ Characteristics } & \multirow{3}{*}{$\begin{array}{l}\text { All } \\
(n=60)\end{array}$} & & \multicolumn{2}{|c|}{ LR free survival } & \multirow{3}{*}{$P$-value ${ }^{\S}$} & \multicolumn{2}{|l|}{ DM free survival } & \multirow[t]{3}{*}{$P$-value ${ }^{\S}$} & \multicolumn{2}{|c|}{ Overall survival } & \multirow[t]{3}{*}{$P$-value ${ }^{\S}$} \\
\hline & & & Median LRFS & 3 years LRFS & & Median DMFS & 3 years & & Median OS & 3 years & \\
\hline & & & (months) & & & (months) & DMFS & & (months) & OS & \\
\hline All patients & & & NR & $61.70 \%$ & & NR & $78.50 \%$ & & NR & $69.20 \%$ & \\
\hline \multicolumn{12}{|l|}{ Pathological type } \\
\hline Adenocarcinoma & 55 & $(91.70 \%)$ & NR & $67.30 \%$ & $<0.001$ & NR & $85.80 \%$ & $<0.001$ & NR & $73.90 \%$ & $<0.001$ \\
\hline Mucinous & 5 & $(8.30 \%)$ & 9 & $0 \%$ & & 10 & $0 \%$ & & 11 & $0 \%$ & \\
\hline \multicolumn{12}{|l|}{ Grade } \\
\hline Grade 1 & 10 & $(16.70 \%)$ & NR & $100 \%$ & $<0.001$ & NR & $100 \%$ & 0.004 & NR & $100 \%$ & $<0.001$ \\
\hline Grade 2 & 38 & $(63.30 \%)$ & NR & $65.80 \%$ & & NR & $83.90 \%$ & & NR & $76 \%$ & \\
\hline Grade 3 & 12 & $(20 \%)$ & 12.5 & $16.70 \%$ & & 25 & $0 \%$ & & 15 & $0 \%$ & \\
\hline \multicolumn{12}{|l|}{$\mathrm{T}$} \\
\hline $\mathrm{T} 1$ & 6 & $(10 \%)$ & NR & $100 \%$ & $<0.001$ & NR & $100 \%$ & 0.059 & NR & $100 \%$ & 0.014 \\
\hline $\mathrm{T} 2$ & 4 & $(6.70 \%)$ & NR & $100 \%$ & & NR & $100 \%$ & & NR & $100 \%$ & \\
\hline T3 & 27 & $(45 \%)$ & NR & $77.80 \%$ & & NR & $83.90 \%$ & & NR & $77.40 \%$ & \\
\hline $\mathrm{T} 4$ & 23 & $(38.30 \%)$ & 15 & $26.10 \%$ & & NR & $58 \%$ & & 20 & $46.10 \%$ & \\
\hline \multicolumn{12}{|l|}{ Lymph node } \\
\hline Negative & 30 & $(50 \%)$ & NR & $86.70 \%$ & $<0.001$ & NR & $100 \%$ & $<0.001$ & NR & $93.30 \%$ & $<0.001$ \\
\hline Positive & 30 & $(50 \%)$ & 13 & $36.70 \%$ & & NR & $53 \%$ & & 16 & $43.80 \%$ & \\
\hline \multicolumn{12}{|l|}{ Stage } \\
\hline Stage I & 10 & $(16.70 \%)$ & NR & $100 \%$ & $<0.001$ & NR & $100 \%$ & $<0.001$ & NR & $100 \%$ & $<0.001$ \\
\hline Stage II & 20 & $(33.30 \%)$ & NR & $80 \%$ & & NR & $100 \%$ & & NR & $90 \%$ & \\
\hline Stage III & 18 & $(30 \%)$ & NR & $50 \%$ & & NR & $100 \%$ & & NR & $66.70 \%$ & \\
\hline Stage IV & 12 & $(20 \%)$ & 9 & $16.70 \%$ & & 10 & $0 \%$ & & 11 & $0 \%$ & \\
\hline \multicolumn{12}{|l|}{ LGR5 } \\
\hline Low & 32 & $(53.30 \%)$ & NR & $100 \%$ & $<0.001$ & NR & $100 \%$ & $<0.001$ & NR & $100 \%$ & $<0.001$ \\
\hline High & 28 & $(46.70 \%)$ & 12 & $17.90 \%$ & & 30 & $33.60 \%$ & & 15 & $24.10 \%$ & \\
\hline \multicolumn{12}{|l|}{ TPX2 } \\
\hline Low & 34 & $(56.70 \%)$ & NR & $97.10 \%$ & $<0.001$ & NR & $94.10 \%$ & $<0.001$ & NR & $100 \%$ & $<0.001$ \\
\hline High & 26 & $(43.30 \%)$ & 13 & $15.40 \%$ & & 30 & $42.70 \%$ & & 15 & $23.20 \%$ & \\
\hline
\end{tabular}

Categorical variables were expressed as number (percentage); NR denote not reached yet; ${ }^{\circledR}$ Log rank test; $P<0.05$ is significant.

A

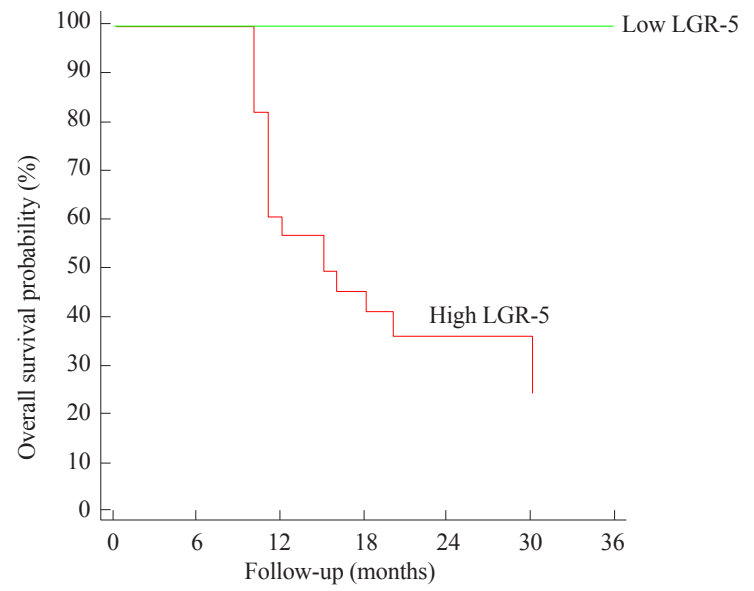

B

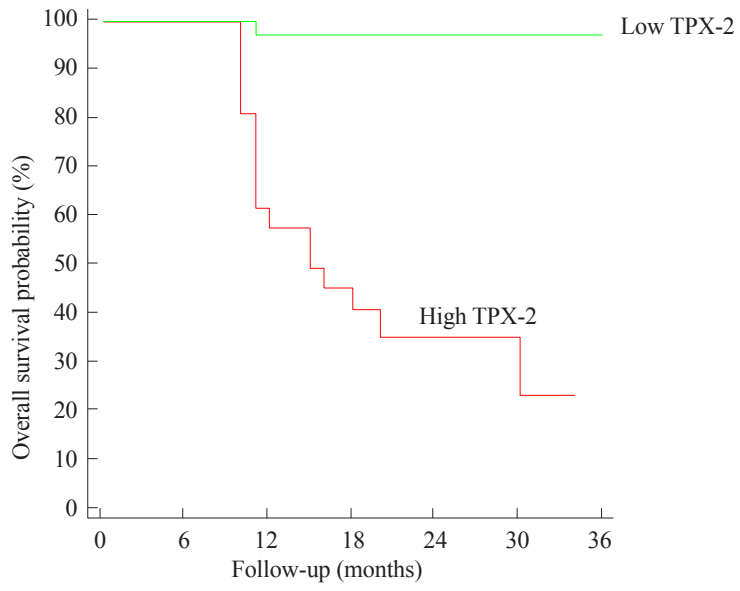

Figure 5 Kaplan-Meier plot of overall survival: (A) stratified according to LGR5; (B) stratified according to TPX2.

up-regulate the expression of matrix metalloproteinases (MMP) family especially MMP2 and MMP9 so increases the invasion and metastases of cancer cells ${ }^{[18]}$.

Aberrant expression of TPX2 leads to improper spindle assembly and chromosomal instability; and these processes might be partly responsible for carcinogenesis ${ }^{[14]}$. However, the precise role of TPX2 in cancer progression is still not fully understood. It has been found that elevated expression of TPX2 promotes tumor growth in pancreatic cancer ${ }^{[39]}$. Also, high levels of TPX2 expression are correlated with the aggressiveness of ovarian and salivary gland cancers $^{[17,40]}$.

TPX2 expression is obviously up-regulated in breast cancer and that TPX2 inhibition can decrease the proliferation, invasion and migration of breast cancer cells through inhibiting expressions of MMP2 and MMP9. Nevertheless, the connection between TPX2 and prognosis, and specific molecular mechanism still need further research $^{[19]}$.

Our results proved that TPX2 plays an important role in promoting tumorigenesis and metastasis of human CRC. It could be used to predict the proliferation capacity of cancer cells and may represent a novel prognostic biomarker and therapeutic target for the disease. Also, the study showed that stem cell biomarker LGR5 expression was positively correlated with the proliferation biomarker TPX2 $(r$ $=+0.489)(P<0.001)$, a recognized nuclear antigen-specific marker of cellular proliferation, suggesting that LGR5-positive cancer cells have higher proliferative activity. As the role of both the stem cell 
biomarker LGR5 and the proliferation biomarker TPX2 is still a point of research and this is the first study to prove the relation between them in CRC progression and prognosis, future studies with more cases are recommended to confirm the benefit of combination of both immunoexpressions in detecting $\mathrm{CRC}$ and assessing its prognosis.

\section{CONCLUSIONS}

In conclusion, the stem cell biomarker "LGR5" is highly expressed in colorectal cancer cells and; may be considered a selective and promising biomarker of SCs and CSCs in the intestinal epithelium. Also, the proliferation biomarker "TPX2" is involved in colon cancer carcinogenesis and metastasis. Moreover, the LGR5 expression is positively correlated with the recognized nuclear antigen-specific marker of cellular proliferation "TPX2" $(r=+0.489)(P<0.001)$. This raises the suggestion that LGR5-positive cancer cells have higher proliferative activity.

Thus, LGR5 may be a potential new therapeutic target for the treatment of colorectal cancer patients, particularly those with advanced cases. TPX2 could serve as a novel prognostic biomarker to predict risk of distant metastases in patients with radical colectomy. Our results might be helpful for understanding the mechanism by which tumorigenesis is initiated, and for enabling targeted treatment of CSCs in order to prevent its progression and improve the patient outcome. Whether LGR5 up-regulation itself contributes to cancer progression or simply is a biological biomarker, this needs further studies on large number of cases to confirm its role in cancer progression.

\section{COMPETING INTERESTS}

The authors declare that they have no competing interests.

\section{REFERENCES}

1. Wu XY, Huang XE, Cao J, Shi L, Xu X, Qian ZY. A predictive model for evaluating responsiveness to pemetrexed treatment in patients with advanced colorectal cancer. Asian Pac J Cancer Prev 2014; 15: 5941-5944.

2. Gong JP, Yang L, Huang XE, Sun BC, Zhou JN, Yu DS et al. Outcomes based on risk assessment of anastomotic leakage after rectal cancer surgery. Asian Pac J Cancer Prev 2014; 15: 707-712.

3. Sideris M, Papagrigoriadis S. Molecular biomarkers and classification models in the evaluation of the prognosis of colorectal cancer. Anticancer Res 2014; 34: 2061-2068.

4. Vaiopoulos AG, Kostakis ID, Koutsilieris M, Papavassiliou AG. Colorectal cancer stem cells. Stem Cells 2012; 30(3): 363-371.

5. Papailiou J, Bramis KJ, Gazouli M, Theodoropoulos G. Stem cells in colon cancer. A new era in cancer theory begins. Int $J$ Colorectal Dis 2011; 26: 1-11.

6. Schneider M, Huber J, Hadaschik B, Siegers GM, Fiebig HH, Schüler J. Characterization of colon cancer cells: a functional approach characterizing CD133 as a potential stem cell marker. BMC Cancer 2012; 12: 96-107.

7. Dorsam RT, Gutkind JS. G-protein-coupled receptors and cancer. Nat Rev Cancer 2007; 7(2): 79-94.

8. Van der Flier LG, van Gijn ME, Hatzis P, Kujala P, Haegebarth A, Stange DE et al. Transcription factor achaete scute-like 2 controls intestinal stem cell fate. Cell 2009; 136(5): 903-912.

9. Brabletz S, Schmalhofer O, Brabletz T. Gastrointestinal stem cells in development and cancer. J Pathol 2009; 217: 307-317

10. Barker N, Huch M, Kujala P, van de Wetering M, Snippert HJ, van Es JH et al. Lgr5 (+ve) stem cells drive self-renewal in the stomach and build long-lived gastric units in vitro. Cell Stem Cell 2010; 6: 25-36.

11. Al-Hajj M, Becker MW, Wicha M, Weissman I, Clarke MF. Therapeutic implications of cancer stem cells. Curr Opin Genet Dev 2004; 14: 43-47.

12. Becker L, Huang Q, Mashimo H. Immunostaining of Lgr5, an intestinal stem cell marker, in normal and premalignant human astrointestinal tissue. Scientific World Journal 2008; 8: 1168-1176.

13. Heidebrecht HJ, Buck F, Steinmann J, Sprenger R, Wacker HH, Parwaresch R. p100: A novel proliferation-associated nuclear protein specifically restricted to cell cycle phases $\mathrm{S}, \mathrm{G} 2$, and $\mathrm{M}$. Blood 1997; 90: 226-233.

14. Neumayer G, Helfricht A, Shim SY, Le HT, Lundin C, Belzil Cet al. Targeting protein for xenopus kinesin-like protein 2 (TPX2) regulates gammahistone 2AX (gamma-H2AX) levels upon ionizing radiation. $J$ Biol Chem 2012; 287: 42206-42222.

15. Neumayer G, Belzil C, Gruss OJ, Nguyen MD. TPX2: Of spindle assembly, DNA damage response, and cancer. Cell Mol Life Sci 2014; 71: 3027-3047.

16. Jiang P, Shen K, Wang X, Song H, Yue Y, Liu T. TPX2 regulates tumor growth in human cervical carcinoma cells. Mol Med Rep 2014; 9: 2347-2351.

17. Caceres-Gorriti KY, Carmona E, Barres V, Rahimi K, Letourneau IJ, Tonin PN et al. RAN nucleo-cytoplasmic transport and mitotic spindle assembly partners XPO7 and TPX2 are new prognostic biomarkers in serous epithelial ovarian cancer. PLoS One 2014; 13: e91000. doi: 10.1371/journal.pone.0091000.

18. Liu Q, Tu K, Zhang H, Zheng X, Yao Y, Liu Q. TPX2 as a novel prognostic biomarker for hepatocellular carcinoma. Hepatol Res 2015; 45(8): 906-918.

19. Yang Y, Li D, Shen N, Yu X, Li J, Song Q et al. TPX2 promotes migration and invasion of human breast cancer cells /Asian Pac $J$ Trop Med 2015; 8(12): 1064-1070.

20. Edge SB, Compton CC. AJCC Cancer Staging Manual. 7th ed. New York (NY): Springer-Verlag, 2010: 143-164.

21. Ueno H, Kajiwara Y, Shimazaki H, Shinto E, Hashiguchi, Y, Nakanishi K et al. New Criteria for Histologic Grading of Colorectal Cancer. Am J Surg Pathol 2012; 36(2): 193-201.

22. Hsu SM, Raine L, Fanger H. Use of avidin-biotin-peroxidase complex $(\mathrm{ABC})$ in immunoperoxidase techniques: a comparison between $\mathrm{ABC}$ and unlabeled antibody (PAP) procedures. $J$ Histochem Cytochem 1981; 29: 577-580.

23. Bu Z, Zheng Z, Zhang L, Li Z, Sun Y, Dong B et al. LGR5 is a promising biomarker for patients with stage I and II gastric cancer. Chin J Cancer Res 2013; 25(1): 79-89.

24. Zhang H, Zhang T, You Z, Zhang Y. Positive Surgical Margin, HPV Persistence, and Expression of Both TPX2 and PD-L1 Are Associated with Persistence/Recurrence of Cervical Intraepithelial Neoplasia after Cervical Conization. PLoS One. 2015; 10(12): e0142868. doi: 10.1371/journal.pone.0142868

25. Wei P, Zhang N, Xu Y, Li X, Shi D, Wang Y et al. TPX2 is a novel prognostic marker for the growth and metastasis of colon cancer. $J$ Transl Med 2013; 11. doi: 10.1186/1479-5876-11-313.

26. Walker F, Zhang HH, Odorizzi A, Burgess AW. LGR5 is a negative regulator of tumourigenicity, antagonizes Wnt signalling and regulates cell adhesion in colorectal cancer cell lines. PLoS One 2011; 6(7): e22733.

27. Aguilera C, Nakagawa K, Sancho R, Chakraborty A, Hendrich B, Behrens A. c-Jun N-terminal phosphorylation antagonises recruitment of the Mbd3/NuRD repressor complex. Nature 2013; 469(7329): 231-235.

28. Al-Kharusi MR, Smartt HJ, Greenhough A, Collard TJ, Emery ED, Williams AC et al. LGR5 promotes survival in human colorectal adenoma cells and is upregulated by PGE2: implications for targeting adenoma stem cells with NSAIDs. Carcinogenesis 2013; 34(5): 1150-1157.

29. De Sousa EMF, Colak S, Buikhuisen J, Koster J, Cameron K, de 
Jong JH et al. Methylation of cancer-stem-cell-associated Wnt target genes predicts poor prognosis in colorectal cancer patients. Cell Stem Cell 2011; 9(5): 476-485.

30. Oskarsson T, Acharyya S, Zhang XH, Vanharanta S, Tavazoie $\mathrm{SF}$, Morris PG et al. Breast cancer cells produce tenascin $\mathrm{C}$ as a metastatic niche component to colonize the lungs. Nat Med 2011; 17(7): 867-874.

31. Nakata S, Campos B, Bageritz J, Bermejo JL, Becker N, Engel F et al. LGR5 is a marker of poor prognosis in glioblastoma and is required for survival of brain cancer stem-like cells. Brain Pathol 2013; 23(1): 60-72.

32. Ryuge S, Sato Y, Jiang SX, Wang G, Kobayashi M, Nagashio R et al. The clinicopathological significance of Lgr5 expression in lung adenocarcinoma. Lung Cancer 2013; 82(1): 143-148.

33. Becker L, Huang Q, Mashimo H. Lgr5, an intestinal stem cell marker, is abnormally expressed in Barrett's esophagus and esophageal adenocarcinoma. Dis Esophagus 2010; 23: 168-174.

34. Ieta K, Tanaka F, Haraguchi N, Kita Y, Sakashita H, Mimori K, Matsumoto T, Inoue H, Kuwano H, Mori M. Biological and genetic characteristics of tumor-initiating cells in colon cancer. Ann Surg Oncol 2008; 15: 638-648.

35. George SR, O’Dowd BF, Lee SP. G-protein-coupled receptor oligomerization and its potential for drug discovery. Nat Rev Drug Discov 2002; 1(10): 808-820.
36. Hanahan D, Weinberg RA. Hallmarks of cancer: the next generation. Cell 2011; 144: 646-674.

37. Yan L, Li S, Xu C, Zhao X, Hao B, Li H, Qiao B. Target protein for Xklp2 (TPX2), a microtubule-related protein, contributes to malignant phenotype in bladder carcinoma. Tumour Biol 2013; 34: 4089-4100.

38. Hsu PK, Chen HY, Yeh YC, Yen CC, Wu YC, Hsu CP et al. TPX2 expression is associated with cell proliferation and patient outcome in esophageal squamous cell carcinoma. $J$ Gastroenterol 2014; 49: 1231-1240.

39. Warner SL, Stephens BJ, Nwokenkwo S, Hostetter G, Sugeng A, Hidalgo $\mathrm{M}$ et al. Validation of TPX2 as a potential therapeutic target in pancreatic cancer cells. Clin Cancer Res 2009; 15: 6519-6528.

40. Shigeishi H, Ohta K, Hiraoka M, Fujimoto S, Minami M, Higashikawa $\mathrm{K}$ et al. Expression of TPX2 in salivary gland carcinomas. Oncol Rep 2009; 21; 341-344.

Peer reviewers: Guangwen Cao, M.D.,Ph.D., Professor of Medicine, Chairman, Department of Epidemiology, Second Military Medical University, 800 Xiangyin Rd., Yangpu District, Shanghai 200433, China; Jian Ming Xu, MD, Affiliated Hospital Cancer Center, Academy of Military Medical Sciences, (The 307 Hospital of PLA Cancer Center), No. 8, Dong Da Avenue, Feng Tai District, Beijing 100071, China. 